\title{
The role of thioredoxin 1 in the mycophenolic acid-induced apoptosis of insulin-producing cells
}

\author{
KH Huh ${ }^{1,2,5}$, Y Cho ${ }^{1,5}$, BS Kim ${ }^{1,3}$, JH Do ${ }^{1}$, Y-J Park ${ }^{1}$, DJ Joo ${ }^{1,2}$, MS Kim ${ }^{1,2}$ and YS Kim, ${ }^{\star 1,2,4}$
}

Mycophenolic acid (MPA) is one of many effective immunosuppressive drugs. However, MPA can induce cellular toxicity and impair cellular function in $\beta$-cells. To explore the effects of MPA and the relation between MPA and Trx-1, we used various methods, including an Illumina microarray, to identify the genes regulated during pancreatic $\beta$-cell death following MPA treatment. INS-1E cells (a pancreatic $\beta$-cell line) and isolated rat islets were treated with MPA for 12,24 , or $36 \mathrm{~h}$, and subsequent microarray analysis showed that (Trx1) gene expression was significantly reduced by MPA. Further, Trx1 overexpression increased the cell viability, decreased the activations of c-jun N-terminal kinase (JNK) and caspase-3 by MPA, and attenuated ROS upregulation by MPA. Furthermore, siRNA knockdown of Trx1 increased MPA-induced cell death and the activations of p-JNK and caspase-3, and MPA significantly provoked the apoptosis of insulin-secreting cells via Trx1 downregulation. Our findings suggest that the prevention of Trx1 downregulation in response to MPA is critical for successful islet transplantation. Cell Death and Disease (2013) 4, e721; doi:10.1038/cddis.2013.247; published online 11 July 2013

Subject Category: Experimental Medicine

Mycophenolic acid (MPA) is a potent, noncompetitive, reversible inhibitor of inosine-5'-monophosphate dehydrogenase (IMPDH), a key enzyme in the purine de novo synthetic pathway of guanosine nucleotides, ${ }^{1,2}$ and is widely used to prevent rejection after solid organ or islet transplantation. ${ }^{3,4}$ MPA effectively induces cell-cycle arrest in the late $G_{1}$ phase in lymphocytes and more potently inhibits lymphocyte proliferation than the proliferations of other cell types. ${ }^{1,5,6}$ However, prolonged guanosine triphosphate (GTP) depletion induces the apoptosis of insulin-secreting cells. ${ }^{6-8}$ Recently, it was suggested that MPA-mediated GTP depletion blocks DNA synthesis and induces $\beta$-cell death, ${ }^{6,7,9,10}$ but the mechanism responsible for MPA-induced $\beta$-cell death was not determined. We previously reported the specific depletion of GTP via the MPA-induced apoptosis of insulin-secreting cells (HIT-T15, RIN-5, INS-1E, and isolated rat islets) and also confirmed that co-treatment with GTP completely blocked MPA-induced cell death, which suggest that MPA inhibits de novo GTP synthesis and depletes GTP. ${ }^{11,12,13}$ In addition, we identified genes expressionally altered during MPA-induced $\beta$-cell death and grouped these genes by cellular function. In particular, the expressions of 386 genes in INS-1E cells and of 234 genes in primary rat islet cells were found to be significantly altered by MPA as determined using an Illumina cDNA microarray. ${ }^{13}$ Further, the expressions of some genes, such as, RhoGDI- $\alpha$, Thioredoxin 1 (Trx1), Bcl2-related protein, and programmed cell death 2 ( $p d c d$ 2), are known to be closely related to MPA-induced $\beta$-cell death. ${ }^{13,14,15}$

Trxs are small $(\sim 12 \mathrm{kDa})$ proteins that are found in several types of cells. These proteins operate in combination with Trx reductase and nicotinamide adenine dinucleotide phosphate (NADPH) as protein disulfide/dithiol reducing systems. ${ }^{16,17}$ In mammals, three members of the Trx family have been identified, namely, Trx1, Trx2 (the mitochondrially localized form), and Sptrx (sperm Trx, also designated p32TrxL). ${ }^{18,19}$ Trx1 is a multifunctional protein that is present in the extracellular milieu, cytoplasm, and nucleus, and has distinct roles in these environments. ${ }^{20}$ The cellular activity of Trx 1 is regulated by its total expression, localization (nucleus or cytosol) and protein-protein interactions, and by posttranslational modification. ${ }^{21}$ In the extracellular environment, Trx1 exhibits chemokine-like activity, ${ }^{22}$ whereas in the cytoplasm, by scavenging reactive oxygen species (ROS) and activating transcriptional factors, Trx 1 is involved in a wide range of cellular responses, such as cell proliferation, apoptosis, and protection. ${ }^{23-26}$ The harmful effects of oxidative stress are considered to be especially relevant for $\beta$-cells because they express only low levels of antioxidant enzymes, such as superoxide dismutase (SOD, which converts superoxide radicals to $\mathrm{H}_{2} \mathrm{O}_{2}$ ), catalase, cellular glutathione peroxidase

\footnotetext{
${ }^{1}$ Research Institute for Transplantation, Yonsei University College of Medicine, Seoul, Republic of Korea; ${ }^{2}$ Department of Transplantation Surgery, Severance Hospital, Yonsei University Health System, Seoul, Republic of Korea; ${ }^{3}$ Department of Internal Medicine, Severance Hospital, Yonsei University Health System, Seoul, Republic of Korea and ${ }^{4}$ BK21 for Medical Science, Yonsei University College of Medicine, Seoul, Republic of Korea

${ }^{*}$ Corresponding author: YS Kim, Department of Transplantation Surgery, Severance Hospital, Yonsei University College of Medicine, 50 Yonsei-ro, Seodaemun-gu, Seoul, 120-752, Republic of Korea. Tel: + 8222228 2115; Fax: + 822313 8289; E-mail: yukim @yuhs.ac or yukim @yumc.yonsei.ac.kr

${ }^{5} \mathrm{KH}$ Huh and $\mathrm{Y}$ Cho contributed equally to this study.

Keywords: MPA; Trx1; pancreatic $\beta$-cell; apoptosis

Abbreviations: ASK-1, apoptosis signal-regulating kinase-1; DCF-DA, dichlorodihydrofluorescein diacetate; Gpx-1, glutathione peroxidase; GTP, guanosine triphosphate; IMPDH, inosine-5'-monophosphate dehydrogenase; JNK, Jun N-terminal kinase; MPA, mycophenolic acid; MTT, 3-(4,5-dimethylthiazol-2-yl)-2, 5-diphenyltetrazolium bromide; NADPH, nicotinamide adenine dinucleotide phosphate; PBS, phosphate-buffered saline; Pdcd2, programmed cell death 2; ROls, reactive oxidative intermediates; ROS, reactive oxygen species; S.E., standard error; siRNA, small interfering RNA; SOD, superoxide dismutase; Trx1, thioredoxin1

Received 04.3.13; revised 07.6.13; accepted 07.6.13; Edited by A Stephanou
} 
(Gpx-1, which detoxifies $\mathrm{H}_{2} \mathrm{O}_{2}$ ), and Trx. ${ }^{27,28}$ Further, the preventions of autoimmune and STZ-induced diabetes by Trx1 overexpression in $\beta$-cells suggest that Trx1 has important effects on $\beta$-cell destruction in type 1 diabetes (T1D) and on genetic susceptibility to T1D, ${ }^{27,29}$ and indicate that Trx1 has a critical role during $\beta$-cell death in T1D.

The objective of this study was to investigate the apoptotic effect of MPA on insulin-producing cells and to examine the role of Trx 1 in this process. To explore these effects of MPA, we used various methods, including an Illumina microarray, to identify those genes regulated during pancreatic $\beta$-cell death following MPA treatment. In order to identify the effects of Trx1 downregulation on MPA-induced apoptosis, we observed the effects of Trx 1 overexpression and knockdown on MPA treatment in rat INS-1E cells (an insulin-producing cell line). In addition, we examined the relationship between Trx1 expression and ROS generation during MPA-induced apoptosis in INS-1E cells.

\section{Results}

The identification of genes modulated by MPA using a microarray. Previously, we reported differentially expressed gene profiles during MPA-induced $\beta$-cell death. ${ }^{13}$ For this analysis, INS-1E cells and isolated primary islets from rats were treated with $40 \mu \mathrm{M}$ MPA for $24 \mathrm{~h}$ or $48 \mathrm{~h}$. INS-1E cells and isolated islets were analyzed using an Illumina RatRef-12 Expression BeadChip. Previous analysis identified genes related to the apoptosis signaling pathway and showed that decreased RhoGDI- $\alpha$ to Rac1 binding increased Rac1 activity. ${ }^{13,30}$ Accumulating evidence indicates that Rac1 has a negative modulatory effect on the metabolic dysfunction of islet $\beta$-cells, especially with respect to the regulation of Nox activation. ${ }^{31}$ Further, recent studies have implicated Nox in the constitutive generation of ROS following the long-term exposure of $\beta$-cells to various stimuli known to cause metabolic dysregulation. ${ }^{32-34}$ In the present study, we grouped genes by molecular function and then focused on the oxidoreductase group, which accounted for many differentially expressed genes. It was found that 19 genes belonging to the oxidoreductase group were expressed at high values ( $> \pm$ twofold versus control cells) $(P<0.05$, $n=4)$. In particular, this analysis confirmed that $\operatorname{Tr} x 1$ gene expression was decreased by MPA (Table 1). These findings suggest that the downregulation of Trx1 by MPA in INS-1E cells is associated with MPA-induced $\beta$-cell apoptosis.

Changes in Trx1 expression during MPA-induced apoptosis. To confirm our microarray results, quantitative real-time PCR (qPCR) was performed after treating INS-1E cells with $10 \mu \mathrm{M}$ MPA for 12,24 , or $36 \mathrm{~h}$. In order to rescue GTP depletion after MPA treatment, $100 \mu \mathrm{M}$ of GTP was co-treated into INS-1E cell for $36 \mathrm{~h}$. Real-time PCR showed that mRNA expression levels decreased to $0.66 \pm 0.03$ at $12 \mathrm{~h}, 0.43 \pm 0.09$ at $24 \mathrm{~h}$, and to $0.20 \pm 0.10$ at $36 \mathrm{~h}$ versus the untreated control (CTL) (Figure 1a). Further, the gene expression level of Trx1 was time-dependently reduced by MPA. However, co-treatment with $10 \mu \mathrm{M}$ MPA plus $100 \mu \mathrm{M}$ GTP effectively prevented loss of Trx1 expression at $36 \mathrm{~h}$ $(0.60 \pm 0.01)$. These results were in line with our Genechip results. To quantify Trx1 protein expression under the same experimental conditions, we immunoblotted total protein lysates. The protein expression of Trx1 was found to decrease in INS-1E cells during MPA-induced cell death, but co-treatment with GTP significantly prevented this Trx1 protein deletion (Figure $1 \mathrm{~b}$ ).

Primary rat islet cells correspond more closely than INS-1E cells to therapeutic islet transplants, and hence we evaluated the effects of MPA on rat islet cells and compared the mechanism of MPA-induced cell death in these primary cultures with that in the INS-1E cell line. Real-time PCR was performed after treating islet cells with $40 \mu \mathrm{M}$ MPA for $12 \mathrm{~h}$,

Table 1 List of genes showing significantly changed expression levels after MPA treatment

\begin{tabular}{|c|c|c|c|c|c|c|}
\hline No. & Definition & Symbol & Transcript & $\begin{array}{c}\text { CTL } \\
\text { intensity }\end{array}$ & $\begin{array}{c}24 \mathrm{~h} \\
\text { intensity }\end{array}$ & Fold \\
\hline 1 & Cytochrome P450 4F5 & Сур4f5 & NM_173124.1 & 249 & 892 & 4.66 \\
\hline 2 & Enoyl coenzyme A hydratase 1, peroxisomal & Ech1 & NM_022594.1 & 6639 & 20842 & 3.58 \\
\hline 3 & Carbonyl reductase 4 & Cbr4 & NM_182672.1 & 1512 & 3984 & 2.51 \\
\hline 5 & Crystallin, lambda 1 & Cryl1 & NM_175757.2 & 225 & 509 & 2.36 \\
\hline 6 & Phytanoyl-CoA hydroxylase & Phyh & NM_053674.1 & 2289 & 4432 & 2.17 \\
\hline 7 & Lactate dehydrogenase $D$ & Ldhd & NM_001008893.1 & 275 & 573 & 2.05 \\
\hline 8 & Acyl-Coenzyme A dehydrogenase, long-chain & Acadl & NM_012819.1 & 3664 & 6936 & 2.03 \\
\hline 9 & Thioredoxin 1 & Txn1 & NM_053800.2 & 52937 & 23322 & -2.06 \\
\hline 10 & $\begin{array}{l}\text { Sulfite oxidase (Suox), nuclear gene encoding mitochondrial protein malic } \\
\text { enzyme } 1\end{array}$ & Suox & NM_031127.3 & 6075 & 2556 & -2.21 \\
\hline 11 & Malic enzyme 1 & Me1 & NM_012600.1 & 2282 & 929 & -2.26 \\
\hline 12 & 3-hydroxy-3-methylglutaryl-coenzyme A reductase & $\mathrm{Hmgcr}$ & NM_013134.2 & 13303 & 4962 & -2.33 \\
\hline 13 & 3-hydroxybutyrate dehydrogenase, type 1 & Bdh1 & NM_053995.3 & 1513 & 561 & -2.58 \\
\hline 14 & 7-dehydrocholesterol reductase & Dhcr7 & NM_022389.2 & 6879 & 2169 & -2.71 \\
\hline 15 & Monoamine oxidase B (Maob) & Maob & NM_013198.1 & 10790 & 2477 & -3.16 \\
\hline 16 & Squalene epoxidase & Sqle & NM_017136.1 & 9633 & 2503 & -3.45 \\
\hline 17 & Sterol-C4-methyl oxidase-like & Sc4mol & NM_080886.1 & 12426 & 3092 & -3.74 \\
\hline 18 & Aldehyde dehydrogenase 1 family, member $A 1$ & Aldh1a1 & NM_022407.3 & 1168 & 244 & -4.54 \\
\hline 19 & Stearoyl-Coenzyme A desaturase 2 & Scd2 & NM_031841.1 & 24966 & 3122 & -5.59 \\
\hline
\end{tabular}

INS-1E cells were treated with $10 \mu \mathrm{M}$ MPA for $24 \mathrm{~h}$. The cDNAs of INS-1E cells were analyzed using an Illumina RatRef-12 Expression BeadChip in quadruplicate 
$24 \mathrm{~h}$, or $36 \mathrm{~h}$ and after co-treating them with $40 \mu \mathrm{M}$ MPA plus $100 \mathrm{uM}$ GTP for $36 \mathrm{~h}$. As is shown in Figure 1a, mRNA expression levels decreased to $0.89 \pm 0.01$ at $12 \mathrm{~h}$, $0.66 \pm 0.03$ at $24 \mathrm{~h}$, and to $0.63 \pm 0.02$ at $36 \mathrm{~h}$ versus the untreated control (CTL) (Figure 1c). Further, although Trx1

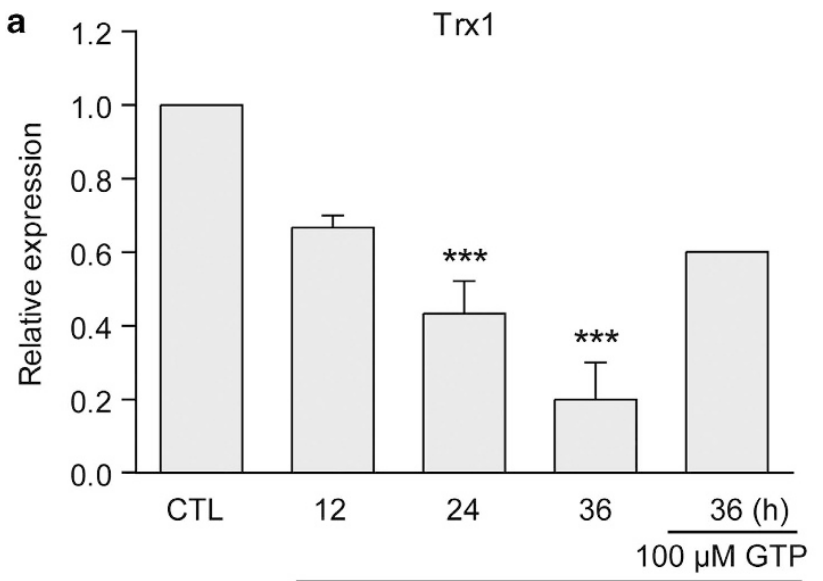

$10 \mu \mathrm{M}$ MPA

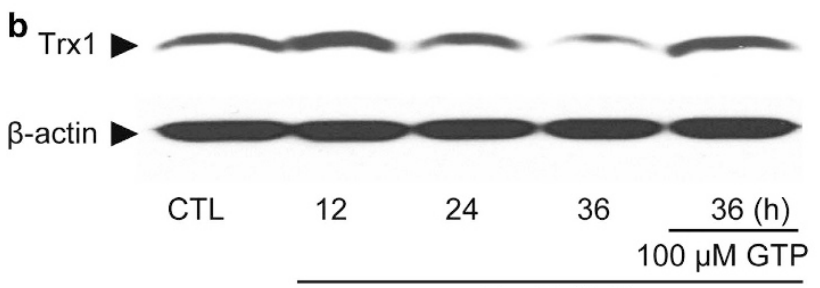

$10 \mu \mathrm{M}$ MPA

c

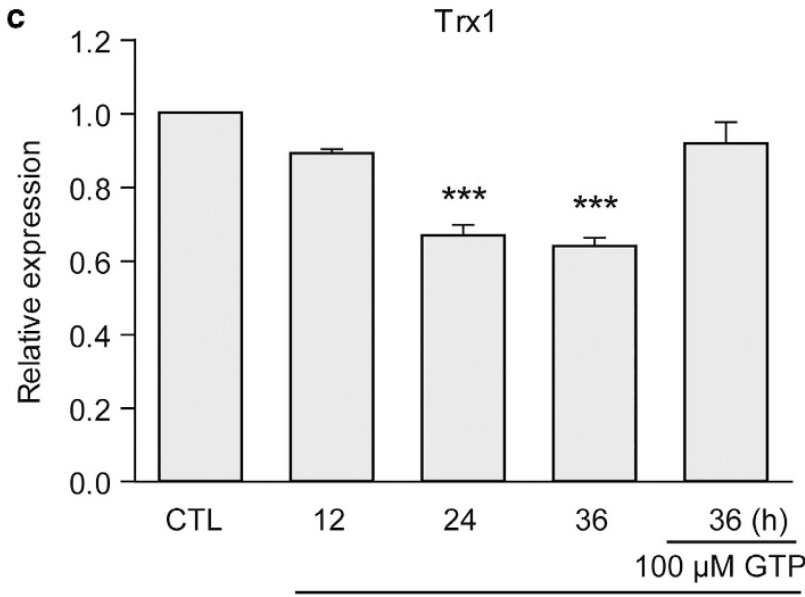

$40 \mu \mathrm{M}$ MPA

d

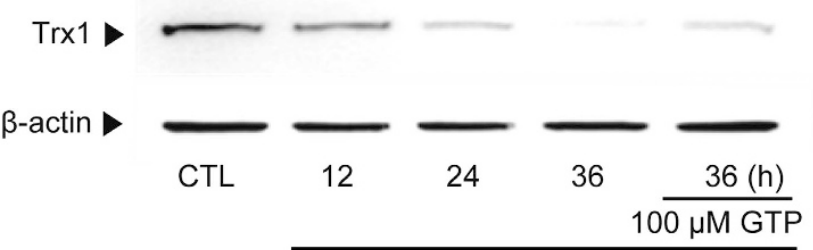

$40 \mu \mathrm{M}$ MPA
mRNA decreased time-dependently after MPA treatment, co-treatment with MPA plus GTP maintained Trx1 mRNA expression at a higher level $(0.92 \pm 0.06$ at $36 \mathrm{~h})$ than treatment with MPA alone. In addition, treatment with MPA decreased Trx1 protein expression in primary islet cells, but co-treatment with MPA plus GTP suppressed this response (Figure 1d).

Using immunohistochemistry, we confirmed that Trx1 protein expression was downregulated during apoptosis in primary rat islets treated with $40 \mu \mathrm{M}$ MPA. To identify $\beta$-cells, islet cluster sections were stained for insulin. It is known that the cytoarchitectures of pancreatic islets are species dependent. In particular, rodent islets are characterized by a predominance of insulin-producing $\beta$-cells in the cores of islet clusters and by scarce alpha, delta, and PP cells in peripheries. ${ }^{35,36}$ As shown in Figure 2, Trx1 (red) expression level in $\beta$-cells (colored green; especially in islet cores) decreased over time after treatment with $40 \mu \mathrm{M}$ MPA for 12, 24 , or 36 h. Quantitative analysis of Trx1/insulin staining ratios showed reduced Trx1 expression in the $\beta$-cells of isolated rat islets. The number of Trx1 and insulin positive cells reduced with MPA treatment time, and the protein expression of Trx1 was especially reduced in $\beta$-cells. However, co-treatment with $40 \mu \mathrm{M}$ MPA plus $100 \mu \mathrm{M}$ GTP increased the number of $\beta$-cells expressing Trx1 protein. Consequentially, Trx1 expressions in $\beta$-cells (isolated rat islets) decreased after MPA treatment. These results agree with the results obtained using the INS-1E cell line and show that reduced Trx1 expression is linked to $\beta$-cell toxicity in response to MPA.

Effects of Trx1 expression on INS-1E cell survival during MPA-induced apoptosis. To investigate the effects of Trx1 expression on the survival of INS-1E cells, we established INS-1E cells stably expressing Trx1 from pcDNA 3.1 and transiently transfected these cells with Trx1 siRNA (Figure 3a). As shown in Figure 3b, although Trx1 overexpression reduced MPA-induced cell death versus the control (transfected with vector only), Trx1 knockdown increased cell death. More specifically, the viability of INS-1E cells decreased to $72 \pm 3.2 \%$ versus control cells after treatment with $10 \mu \mathrm{M}$ MPA for $24 \mathrm{~h}$, but the viability of Trx1-overexpressing cells was similar to that of the control

Figure 1 Changes in Trx1 gene and protein expression levels in INS-1E cells and isolated rat islets after MPA treatment. $(\mathbf{a}, \mathbf{b})$ INS-1E cells were treated with $10 \mu \mathrm{M}$ MPA for $12 \mathrm{~h}, 24 \mathrm{~h}$, or $36 \mathrm{~h}$ or co-treated with $10 \mu \mathrm{M}$ MPA plus $100 \mu \mathrm{M}$ GTP for $36 \mathrm{~h}$. (c, d) Islets isolated from a rat were treated with $40 \mu \mathrm{M}$ MPA for $12 \mathrm{~h}, 24 \mathrm{~h}$, or $36 \mathrm{~h}$ or co-treated with $10 \mu \mathrm{M}$ MPA plus $100 \mu \mathrm{M}$ GTP for $36 \mathrm{~h}$. (a) To quantify Trx1 gene expression in INS-1E cells, mRNA levels were assessed by qPCR. Trx1 gene expression levels gradually diminished after MPA treatment, but this effect was inhibited by GTP co-treatment. Results are the means \pm SEMs of three independent experiments. ${ }^{* \star *} P<0.0001$ versus the untreated control (CTL). GAPDH was used as an internal control to normalize gene expressions. (b) Cell lysates $(40 \mu \mathrm{g})$ were loaded onto gels and immunoblotted. In INS-1E cells, Trx1 protein levels were progressively reduced by MPA treatment. $\beta$-Actin was used to confirm equal loading. (c) The mRNA expressions of $T r x 1$ in islets were evaluated by $\mathrm{qPCR}$. Trx1 gene expression decreased progressively after MPA treatment. ${ }^{* * *} P<0.0001$ versus CTL. (d) Cell lysates $(40 \mu \mathrm{g})$ were loaded onto gels and immunoblotted. In isolated islets, Trx1 protein levels were progressively reduced by MPA treatment 


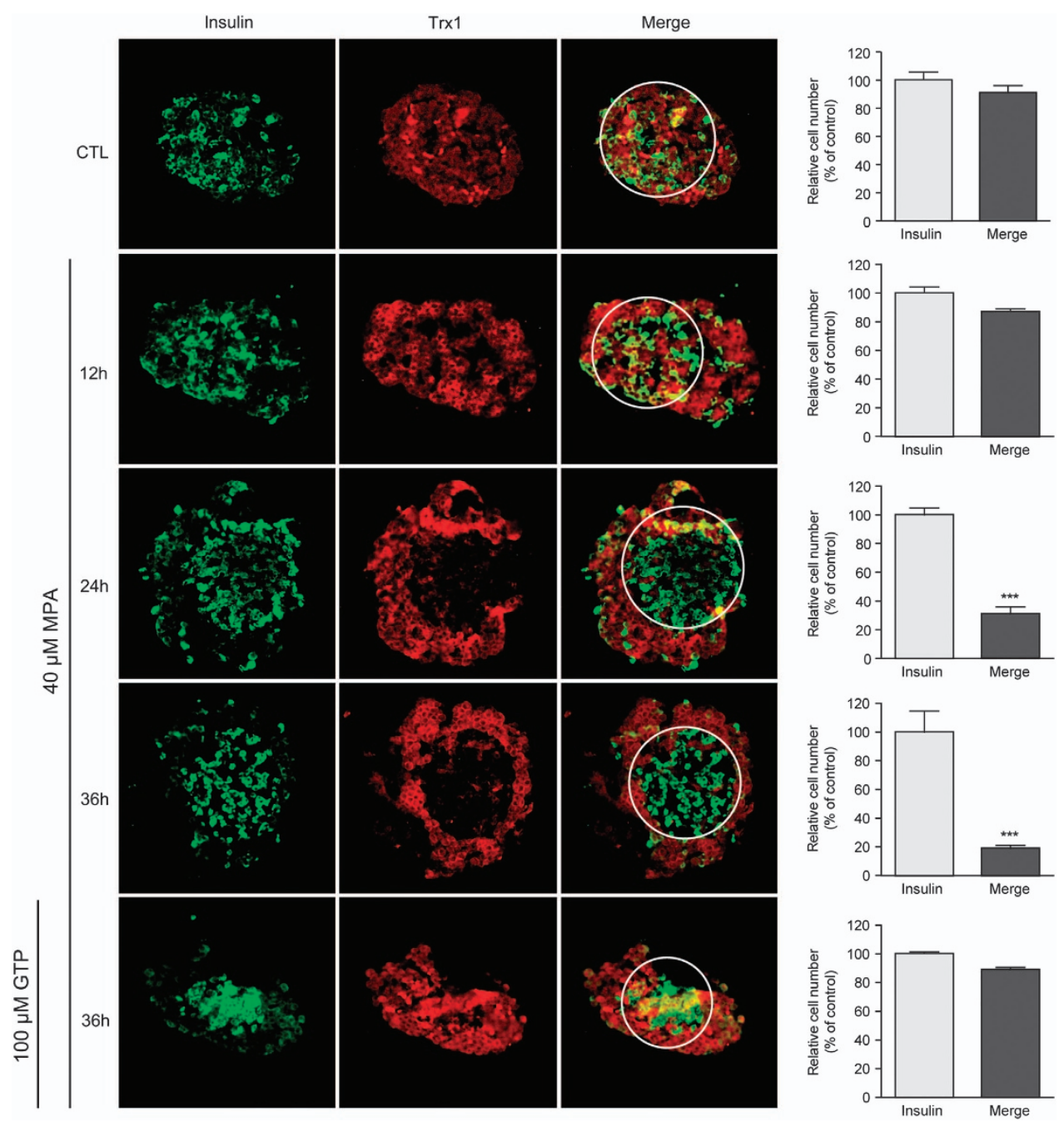

Figure 2 The expression of Trx1 was diminished in the $\beta$-cells of isolated rat islets by MPA. Isolated rat islet clusters were treated with $40 \mu \mathrm{M} \mathrm{MPA}$ alone for 12, 24, or $36 \mathrm{~h}$ or co-treated with $40 \mu \mathrm{M}$ MPA plus $100 \mu \mathrm{M}$ GTP for $36 \mathrm{~h}$. At the indicated times, islets were fixed in $4 \%$ paraformaldehyde and sectioned at $4-\mu \mathrm{m}$. Insulin (green) staining shows $\beta$-cell locations and population sizes in isolated rat islets. Trx1 (red) staining decreased time-dependently after treating $\beta$-cells with MPA, but this decrease was inhibited when GTP was co-treated (after $36 \mathrm{~h}$ of treatment). The bar graphs show numbers of insulin-stained cells (black bar), and Trx1 and insulin co-stained cells (gray dotted blocks). Cell numbers were counted in 3-4 images per experiment, and experiments were performed in triplicate. Values are means \pm SEMs $\left({ }^{* \star *} P<0.001\right)$

$(98.5 \pm 0.5 \%$ of control at $24 \mathrm{~h})$. These results suggest that Trx1 is involved in MPA-induced $\beta$-cell apoptosis.

Changes in Trx1 expression were closely associated with MAPK-dependent apoptosis. In earlier studies, we found that MPA induced apoptosis in several pancreatic $\beta$-cell lines via JNK activation, ${ }^{12,13,37}$ and thus we investigated the effect of Trx1 expression on the MAPK signaling pathway. After treating INS-1E cells and the Trx1-overexpressing INS-1E cell line with $10 \mu \mathrm{M}$ MPA for $12 \mathrm{~h}, 24 \mathrm{~h}$, or $36 \mathrm{~h}, \mathrm{p}-\mathrm{MKK} 4 / 7$, p-JNK, and cleaved caspase-3 protein levels were measured by western blotting. $p-M K K 4 / 7$ was observed at $12 \mathrm{~h}$ and its level was increased at $24 \mathrm{~h}$. However, this increase was not observed at any time in Trx1-overexpressing cells (Figure 4a). p-JNK protein levels were dramatically increased at $24 \mathrm{~h}$ and slightly more increased at $36 \mathrm{~h}$ versus untreated controls, but its levels were increased only at $36 \mathrm{~h}$ in Trx1-overexpressing cells (Figure $4 b$ ). The expression of cleaved caspase-3 was markedly lower in Trx1-overexpressing cells than in INS-1E cells (Figure 4c). Further, Trx1 knockdown increased the activations of MKK4/7, JNK, and caspase-3 (Supplementary data 1). These results show that Trx1 expression regulates MPA-induced apoptosis via an MAPK-dependent signaling pathway.

ROS level measurements in INS-1E cells treated with MPA. The key biological activities of Trx1 include antioxidative, antiapoptotic, and growth-stimulatory effects, which are attributable to its interactions with nuclear factor $-\kappa \mathrm{B}$ (NF- $\kappa \mathrm{B}$ ), apoptosis signal regulating kinase-1 (ASK-1), and hypoxia-inducible factor- $1 .{ }^{24,37,38}$ The most distinctive role of Trx1 concerns the repair of proteins oxidized by reactive oxygen-containing intermediates. Therefore, we used DCF-DA to detect cellular ROS in INS-1E cells treated with MPA. Cellular ROS generation was observed by fluorescence microscopy after treating INS-1E and Trx1-overexpressing INS-1E cells with $10 \mu \mathrm{M}$ MPA. As shown in Figure $5 \mathrm{a}$, cellular 
ROS increased during MPA-induced apoptosis, whereas ROS generation was obviously less in Trx1-overexpressing cells. To quantify intracellular ROS levels more precisely, we used fluorescence spectrophotometry. Intracellular ROS levels in INS-1E cells increased in a time-dependent manner after treatment with $10 \mu \mathrm{M}$ MPA for $12 \mathrm{~h}, 24 \mathrm{~h}$, or $36 \mathrm{~h}$ (by $104.3 \pm 0.9 \%, 118.3 \pm 9.8 \%$, and $137.0 \pm 8.7 \%$ of the untreated control levels, respectively). However, ROS generation in Trx1-overexpressing cells remained at the

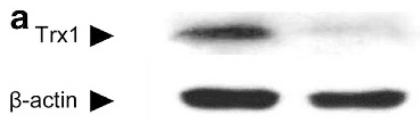

CTL SIRNA
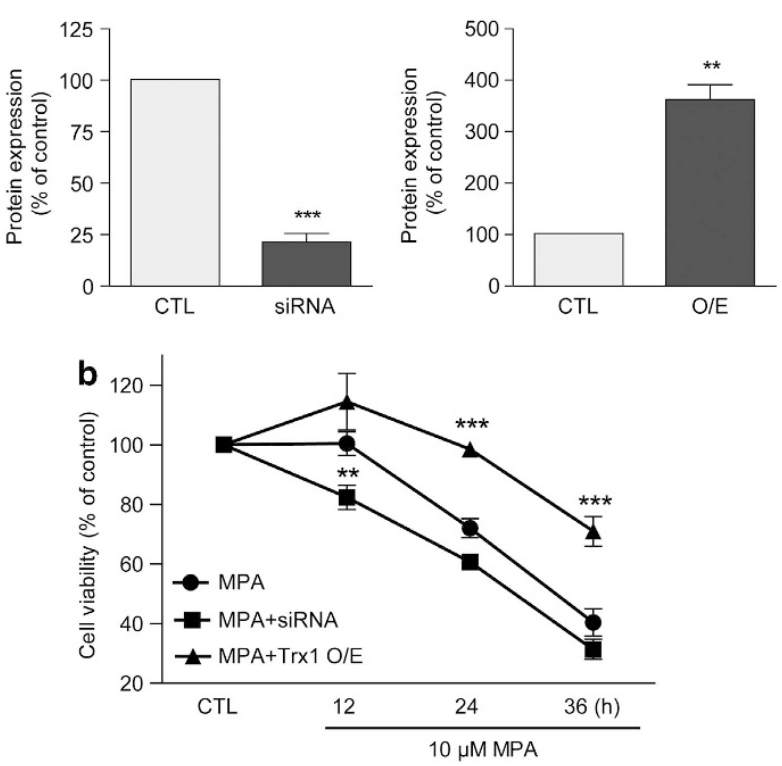

Figure 3 The effects of Trx1 gene knockdown and Trx1 overexpression in INS-1E cells. (a) INS-1E cells were either mock transfected (Mock) or transfected with Trx1 siRNA (siTrx1) or full-length Trx1 cDNA (Trx1 O/E). Results are presented as means \pm SEMs of three independent experiments performed in duplicate. ${ }^{* \star} P<0.01$; ${ }^{* \star *} P<0.001$ compared with mock-transfected cells (Mock). (b) Cells were treated with $10 \mu \mathrm{M}$ MPA for the indicated times, and cell viabilities were measured using an MTT assay. The survival rate of Trx1-overexpressing INS-1E cells treated with MPA was greater than that of cells treated with MPA. However, the survival rate of Trx1 knockdown cells was poorer than that of MPA-treated cells. ${ }^{\star \star} P<0.01$ versus MPA-treated cells at $12 \mathrm{~h}$, ${ }^{\star \star \star} P<0.001$ versus MPA-treated cells at $24 \mathrm{~h}$ and $36 \mathrm{~h}(n=4)$

Figure 4 Expression levels of p-MKK4/7, p-JNK, and cleaved caspase-3 following MPA treatment. INS-1E cells and INS-1E cells overexpressing Trx1 were treated with $10 \mu \mathrm{M}$ MPA for 12,24 , or $36 \mathrm{~h}$. Total protein lysates were western blotted. Bar graphs represent quantitative differences in expressions of p-MKK4/7, p-JNK, and cleaved caspase-3. Results are means \pm SEMs $(n=3) .{ }^{*} P<0.01$, ${ }^{* * \star} P<0.001$ versus CTL. (a) $\mathrm{P}-\mathrm{MKK} 4 / 7$ expression was higher in INS-1E cells than in cells overexpressing Trx1. Whereas $p-M K K 4 / 7$ was expressed in INS-1E cells, it was not expressed in cells overexpressing Trx1. (b) P-JNK levels were higher at $24 \mathrm{~h}$ and $36 \mathrm{~h}$ in INS-1E cells than in cells overexpressing Trx1, and P-JNK was only expressed slightly at $36 \mathrm{~h}$ in Trx1-overexpressing cells. (c) Increases in cleaved caspase-3 levels in Trx1-overexpressing cells were lower than in INS-1E cells. Equal loading was confirmed using JNK and $\beta$-actin untreated control level at all times $(99.7 \pm 4.5 \%$, $107.0 \pm 9.0 \%$, and $110.3 \pm 4.3 \%$ of untreated controls, respectively) (Figure 5b). These results show that Trx1 overexpression blocked ROS generation during MPAinduced $\beta$-cell apoptosis.

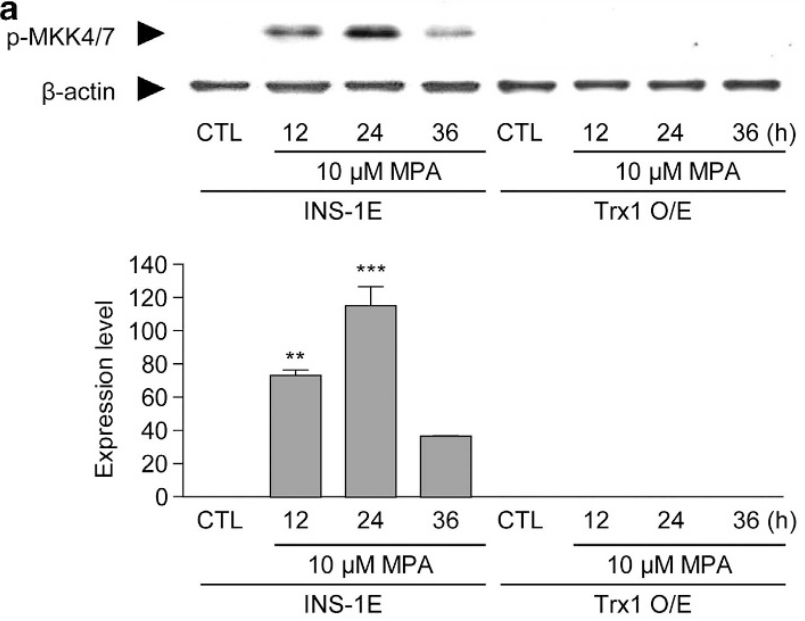

b
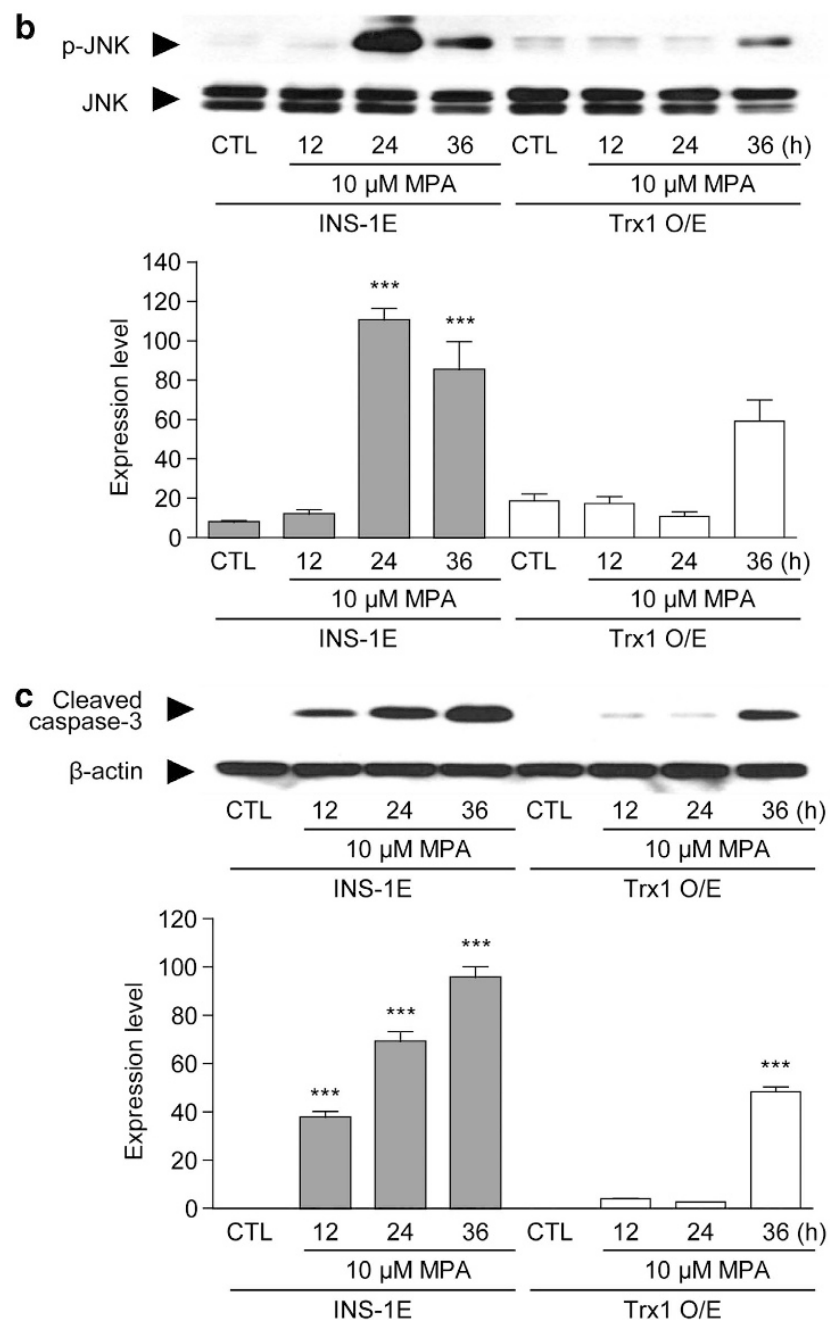
a

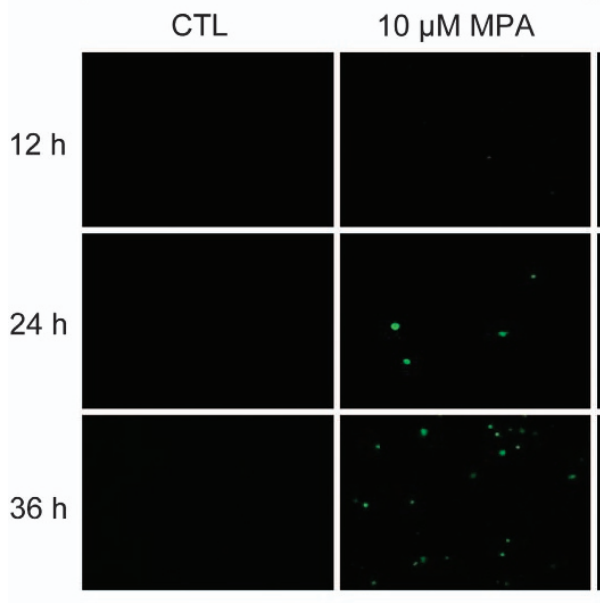

INS-1E

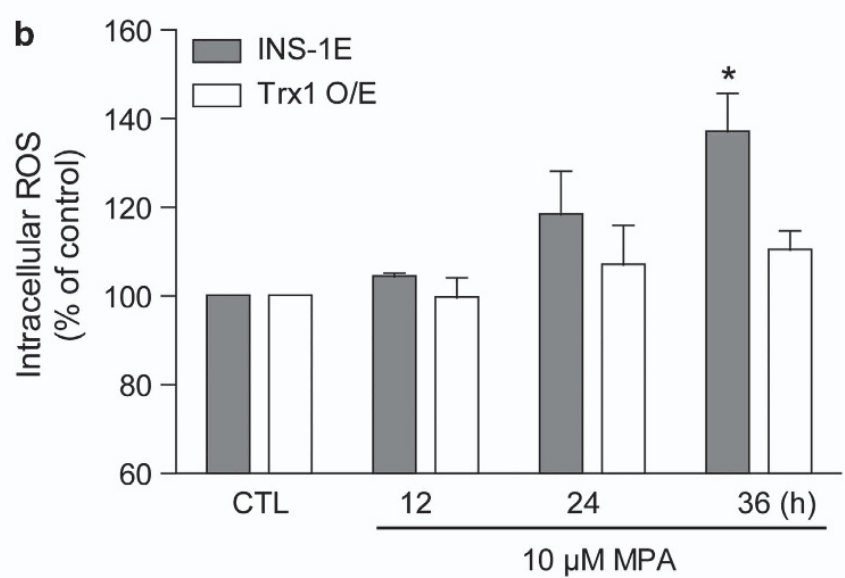

Figure 5 ROS levels in INS-1E cells and INS-1E cells overexpressing Trx 1 following MPA treatment. (a) Both cell lines were treated with $5 \mu$ M DCF-DA for 30 min and then treated with $10 \mu \mathrm{M}$ MPA for 12, 24, or $36 \mathrm{~h}$. ROS levels were detected by fluorescence microscopy. ROS generation was increased dose- and time-dependently by MPA, but this increase was attenuated in Trx1-overexpressing cells. (b) Intracellular ROS levels were measured by fluorescence spectrophotometry. After treatment with MPA for the indicated times, cells were incubated with $10 \mu \mathrm{M}$ DCF-DA for $30 \mathrm{~min}$. ROS levels were elevated in MPA-treated INS-1E cells, but not in Trx1-overexpressing cells. Results are means \pm SEMs $\left(n=3,{ }^{*} P<0.05\right)$

\section{Discussion}

Although islet transplantation is more widely accessible and reproducible than pancreatic transplantation, it presents several issues in the clinical setting. In particular, transplants are susceptible to drug-induced toxicity and might be physiologically inadequate. MPA-induced $\beta$-cell toxicity can also affect islet graft survival, ${ }^{6,7}$ but the signal transduction mechanisms responsible for MPA-induced $\beta$-cell toxicity have not been elucidated. In the present study, we investigated the role of Trx1 in MPA-induced $\beta$-cell apoptosis. In particular, we examined (1) changes in Trx1 expression during MPAinduced apoptosis, (2) the effects of Trx1 overexpression and knockdown on the effects of MPA treatment in the rat insulin-producing cell line INS-1E, and (3) the relationship between Trx1 expression and ROS generation in INS-1E cells during MPA-induced apoptosis. This study has two major findings. First, it demonstrates that MPA reduces Trx1 expression at the protein and gene levels in INS-1E cells and in isolated rat islets. Second, it shows that cell viability is restored by Trx1 overexpression, therefore preventing MPAinduced apoptosis via the MAPK pathway and suppressing ROS generation in response to MPA. Using the microarray technique, we found that numerous genes could be involved in the death of insulin-secreting cells exposed to MPA. As described in the introduction, $\operatorname{Tr} x 1$ is a candidate antiapoptotic gene in insulin-secreting cells ${ }^{13}$ and probably exerts its antiapoptotic effect on the ischemic-reperfused hearts via its antioxidant and ASK-1 inhibitory effects. Further, treatment with Trx1 before reperfusion markedly inhibits p38 MAPK activity. ${ }^{39}$ In addition to its activity as an oxidoreductase, recent in vitro studies have demonstrated that Trx1 directly interacts with and inhibits the activity of ASK-1, a mitogenactivated protein kinase that activates the proapoptotic kinases, MAPK, and JNK. ${ }^{24,40-42}$ In this study, we found that modulations of Trx1 expression affected $\beta$-cell viability and the MAPK pathway after MPA treatment. Together, our findings and those described above indicate that Trx1 is 
associated with MPA-induced apoptosis via the MAPK signaling pathway in insulin-secreting cells.

Hotta et al. ${ }^{27}$ showed that Trx1 overexpression markedly reduced the incidence of diabetes but failed to prevent the development of insulitis. This result suggests that the autoimmune destruction of pancreatic $\beta$-cells in type 1 diabetes is at least partially mediated by reactive oxidative intermediates (ROIs) and that this mediation can be blocked by $\operatorname{Trx} 1 .^{28}$ In the islet transplantation experiment, Trx-overexpressed islets showed better glycemic control and longer graft survival, indicating that Trx has a strong cytoprotective effect on islets. ${ }^{29}$ These effects may reflect the multiple biological functions of Trx, which has both antioxidative and antiapoptotic activities. In the present study, Trx1 expression was inhibited by MPA, and the overexpression of Trx1 inhibited MPA-induced apoptosis by activating the JNK pathway, which suggests that pancreatic $\beta$-cell viability could be improved by Trx1 overexpression during MPA-induced apoptosis. In further studies, we suggest ASK-1 and TXNIP immunoassays be used to determine how MPA affects the expressions of these proteins, and that an additional study be undertaken to determine the nature of the relation between RhoGDI- $\alpha$ and Trx1, and the mechanism(s) responsible for regulating these genes.

Summarizing, we found MPA reduces the expression of Trx1 at the protein and gene levels, and that this downregulation leads to the apoptosis of insulin-secreting cells via the MKK4/7-JNK pathway. Further, our findings indicate Trx1 might mitigate MPA-induced islet cell death and indicate that further studies are needed to evaluate the effects of Trx1 modulation in transplant models.

\section{Materials and Methods}

Cells and culture reagents. Cells were maintained at $37^{\circ} \mathrm{C}$ in a $5 \% \mathrm{CO}_{2}$ humidified incubator. INS-1E insulinoma rat pancreatic $\beta$-cells were cultured in RPMI-1640 medium containing 10\% fetal bovine serum (FBS) (Gibco, Grand Island, NY, USA), $100 \mathrm{units} / \mathrm{ml}$ penicillin, and $100 \mu \mathrm{g} / \mathrm{ml}$ streptomycin, and cells that overexpressed Trx1 were grown in RPMI-1640 medium containing 10\% FBS and $0.2 \mathrm{mg} / \mathrm{ml} \mathrm{G} 418$.

Islet isolation and primary cell culture. The pancreas of a Lewis rat (250-350 g) was digested using collagenase P (Roche, Indianapolis, IN, USA), and the islets so obtained were purified using three different Histopaque (Sigma Chemical Co., St Louis, MO, USA) gradients. Islets were maintained in RPMI-1640 medium containing 10\% FBS (Gibco), 100 units $/ \mathrm{ml}$ penicillin, and $100 \mu \mathrm{g} / \mathrm{ml}$ streptomycin in a humidified $5 \% \mathrm{CO}_{2}$ atmosphere at $37^{\circ} \mathrm{C}$.

Illumina microarray gene analysis. Microarray analysis was performed using an Illumina RatRef-12 Expression BeadChip (Illumina, San Diego, CA, USA), according to the manufacturer's instructions (Macrogen, Seoul, Korea). Biotinylated cRNAs were prepared from $0.55 \mu \mathrm{g}$ of total RNA using an Illumina Total Prep RNA Amplification Kit (Ambion, Austin, TX, USA). Following fragmentation, $0.75 \mu \mathrm{g}$ of cRNA was hybridized to the Illumina RatRef-12 Expression BeadChip (Illumina). Arrays were scanned using an Illumina Bead Array Reader Confocal Scanner. Array data export processing and analysis were performed using Illumina BeadStudio v3.1.3 (Gene Expression Module v3.3.8, Stratagene, CA, USA).

Total RNA isolation. Following medium aspiration, INS-1E cells were lysed directly in culture dishes by adding TRIzol reagent (Invitrogen, Carlsbad, CA, USA). Lysed samples were incubated for $5 \mathrm{~min}$ at room temperature and then mixed with chloroform in a tube by vortexing for $15 \mathrm{~s}$. Tubes were centrifuged at $12000 \times g$ for $15 \mathrm{~min}$ at $4^{\circ} \mathrm{C}$, and supernatants were transferred into new tubes containing isopropanol and then incubated at room temperature for $10 \mathrm{~min}$. Samples were then centrifuged at $12000 \times g$ for $10 \mathrm{~min}$ at $4^{\circ} \mathrm{C}$. The supernatants obtained were discarded and pellets were washed in 70\% ethanol and lysed in RNase-free water.

RT-PCR and quantitative real-time PCR. Total RNA was reverse transcribed using oligo-dT and a M-MLV Reverse Transcriptase (Invitrogen) protocol, and PCR was performed using Bioneer Accupower PCR PreMix (Bioneer, Korea). Real-time PCR was performed using CDNA, a TaqMan probe, and Real-time PCR master mix (QPK-101, TOYOBO, Osaka) using the Taqman assay protocol. Transcript values and $\mathrm{Ct}$ values were normalized against GAPDH and expressed as fold differences versus controls. The following Trx1 sequences were used: sense, $5^{\prime}$-CTTTCATTCCCTCTGTGACAAGTATTC- ${ }^{\prime}$, antisense, $5^{\prime}$-TTATAGAACTGGAAGGTCGGCATG- $3^{\prime}$, and the sequence of the Trx1 Taqman probe was $5^{\prime} p$-Fam-CAGCAACATCCTGGCAGTCATCCACG-BHQ-1-3' $F$. The following GAPDH sequences were used: sense, 5'-GTGATGCTGGTGCTGAG TATGTC-3' ${ }^{\prime}$, antisense $5^{\prime}$-GCGGAAGGGGCGGAGATG-3' , and the sequence of the GAPDH Taqman probe was 5'a-Hex-ACCCTTCAGGTGAGCCCCAG CCTT-BHQ-1-3'H.

Western blot analysis. Protein extracts from the INS-1E cell line were prepared using RIPA buffer containing $50 \mathrm{mM}$ Tris- $\mathrm{HCl}(\mathrm{pH} 7.5), 150 \mathrm{mM} \mathrm{NaCl}$, $1 \%$ Nonidet P-40, $0.5 \%$ sodium deoxycholic acid, and $0.1 \%$ SDS. Proteins were boiled for $5 \mathrm{~min}$, separated by $10-15 \%$ SDS-PAGE, and blotted onto polyvinylidene difluoride membranes. Proteins were detected using the following primary antibodies: Trx1 (1:1000), cleaved caspase-3 (1:1000), p-Jun N-terminal kinase (JNK)/JNK (1:1000), p-MKK4/7 (1:1000) (Cell Signaling Technology, Beverly, MA, USA), and $\beta$-actin $(1: 10000)$ (Sigma). Protein bands were detected using an Immobilon Western Chemiluminescent HRP substrate kit (Millipore Corporation, Billerica, MA, USA).

Fluorescent immunohistochemistry. Primary isolated islets were treated with $40 \mu \mathrm{M} \mathrm{MPA}$, fixed in $4 \%$ paraformaldehyde, and dehydrated using a 10,20 , and $30 \%$ sucrose series overnight. The sucrose solution was then removed from tubes, and $\sim 500 \mu \mathrm{l}$ of Tissue Tek Optimal Cutting Temperature (OCT) solution (Thermo Fisher Scientific, Waltham, MA, USA) was added to islets. The OCT-embedded islets were stored at $-80^{\circ} \mathrm{C}$. Sections $(4-\mu \mathrm{m}$ thick) were then cut on a cryostat, placed on silanized slides, and permeabilized and blocked with $0.5 \% \mathrm{BSA}$ in PBS. Slides were incubated overnight at $4{ }^{\circ} \mathrm{C}$ with a primary polyclonal antibody against Trx1 (Cell Signaling) diluted 1:50 with blocking solution (0.5\% BSA in PBS). Slides were then washed, incubated with an Alexa Fluor 568 goat anti-rabbit antibody (Invitrogen), and then with another primary polyclonal antibody against Insulin (Santa Cruz Biotechnology, Inc.) diluted 1:100. Slides were then washed and incubated with an Alexa Fluor 488 goat anti-mouse antibody (Invitrogen).

Fluorescence microscopy. Fluorescence microscopic images of fixed cells were captured using an Olympus IX71 fluorescence microscope equipped with a DP71 camera and DP-BSW Application software (Olympus Corporation, Tokyo, Japan).

Trx1 gene cloning. In vitro Trx1 transcription templates were amplified by PCR from INS-1E cDNA using 5'-TCCAATGTGGTGTTCCTTGA-3' (forward) and $5^{\prime}$-ACCAGAGAACTCCCCAACCT-3' (reverse). PCR products were cloned into mammalian and bacterial expression vectors using flanking restriction sites engineered into the PCR oligonucleotides. After subcloning cDNA into pcDNA 3.1 vector, the insert was fully sequenced using the dideoxy nucleotide chain termination method and Taq DNA polymerase. The vector was transfected into insulin-secreting cells over $2 \mathrm{~h}$ using $4 \mu \mathrm{l}$ of Lipofectamine 2000 (Invitrogen) in $200 \mu \mathrm{l}$ of serum-free culture medium.

Trx1 silencing. INS-1E cells $\left(1 \times 10^{6} /\right.$ well) cultured in six-well plates were transiently transfected with either small interfering RNAs (siRNAs) targeting Trx1 or scrambled negative control siRNAs. All siRNAs were purchased from QIAGEN Korea Ltd (Seoul, Korea). The following Trx1 sequences were used: sense, 5'-GGGAGACAAGCUUGUGGUATT-3' and antisense, 5'-UACCACAAGCUUGU CUCCCGC-3'. Cells were transfected using Lipofectamine 2000 Reagent and Opti-MEM (Gibco) and analyzed by immunoblotting $\sim 24 \mathrm{~h}$ later.

Cell viability analysis. Cell viabilities were determined using an MTT (3-(4,5-dimethylthiazol-2-yl)-2,5-diphenyltetrazolium bromide) assay. Briefly, cells 
were seeded in a 24-well plate at a density of $2 \times 10^{5}$ cells/well and treated with $10 \mu \mathrm{M}$ of MPA (Sigma) for $12 \mathrm{~h}, 24 \mathrm{~h}$, or $36 \mathrm{~h}$ at $37^{\circ} \mathrm{C}$. MTT solution was added to each well to a final concentration of $1 \mathrm{mg} / \mathrm{ml}$ and incubated for $1 \mathrm{~h}$ at $37^{\circ} \mathrm{C}$. The formazan crystals formed were dissolved in Detergent Reagent (Trevigen, Gaithersburg, MD, USA), and absorbance at $540 \mathrm{~nm}$ was measured using an ELISA plate reader (Molecular Devices, Palo Alto, CA, USA).

Measurement of intracellular ROS production. The peroxidesensitive fluorescent probe 2,7-dichlorodihydrofluorescein diacetate (DCF-DA; Molecular Probes, Carlsbad, CA, USA) was used to assess the generation of intracellular ROS. To observe intracellular ROS generation, treatment-naive INS-1E cells and cells overexpressing Trx1 were grown in six-well plates at a density of $7 \times 10^{5} \mathrm{cells} /$ well, treated with 10,40 , or $80 \mu \mathrm{M}$ of MPA for 12,24 , or $36 \mathrm{~h}$, incubated at $37^{\circ} \mathrm{C}$ for $30 \mathrm{~min}$ in the dark in serum-free medium containing $5 \mu \mathrm{M}$ DCF-DA, and washed three times with phosphate-buffered saline (PBS). Fluorescence microscopic images were captured using an OlympusIX71 fluorescence microscope (Olympus Corporation). To quantify ROS levels, treatment-naive INS-1E cells and cells over-expressing Trx1 were grown in 96-well plates at a density of $4 \times 10^{4}$ cells/well, incubated with $10 \mu \mathrm{M}$ DCF-DA at $37^{\circ} \mathrm{C}$ for $30 \mathrm{~min}$ in the dark, and treated with $10 \mu \mathrm{M}$ MPA for 12,24 , or $36 \mathrm{~h}$. Fluorescence was measured using a luminescence spectrophotometer (Perkin Elmer LS50B, Wellesley, USA) and at excitation and emission wavelengths of 485 and $530 \mathrm{~nm}$, respectively. ROS levels were calculated as percentage increases versus untreated control levels.

Statistical analysis. Results are presented as means \pm SEMs. One-way ANOVA and the post hoc Student's $t$-test were used to determine the significance of differences between means. Statistical significance was accepted for $P$-values of $<0.05$, and the analysis was conducted using GraphPad Prism software (GraphPad Software, Inc., CA, USA).

\section{Conflict of Interest}

The authors disclose the following relevant financial relationships: YC and JHD are research associates supported by Yonsei University IACF (7-2006-0253, 7-2012-0144); MSK has received grants from Novartis, Roche and Astellas; YSK has received grants from Astellas, Novartis, Wyeth, Pfizer, Roche, and CKD. The remaining authors declare no conflict of interest.

Acknowledgements. This work was supported by a National Research Foundation of Korea (NRF) grant funded by the Korea government (MEST) (2011-0023964).

\section{Author Contributions}

KH Huh, Y-J Park, and YS Kim conceived and designed the experiments, Y Cho and JH Do performed the experiments, Y Cho, JH Do, KH Huh, and Y-J Park analyzed the data, and DJ Joo, KH Huh, MS Kim, and YS Kim contributed reagents, materials, or analysis tools. The paper was written by Y Cho, KH Huh, BS Kim, and YS Kim.

1. Allison AC, Eugui EM. Mycophenolate mofetil and its mechanisms of action. Immunopharmacology 2000; 47: 85-118.

2. Villarroel MC, Hidalgo M, Jimeno A. Mycophenolate mofetil: An update. Drugs Today 2009; 45: 521-532.

3. Sollinger HW. Mycophenolate mofetil. Kidney Int Suppl 1995; 52: S14-S17.

4. Guerra G, Srinivas TR, Meier-Kriesche HU. Calcineurin inhibitor-free immunosuppression in kidney transplantation. Transpl Int 2007; 20: 813-827.

5. Gu JJ, Gathy K, Santiago L, Chen E, Huang M, Graves LM et al. Induction of apoptosis in IL-3-dependent hematopoietic cell lines by guanine nucleotide depletion. Blood 2003; 101: 4958-4965.

6. Li G, Segu VB, Rabaglia ME, Luo RH, Kowluru A, Metz SA. Prolonged depletion of guanosine triphosphate induces death of insulin-secreting cells by apoptosis. Endocrinology 1998; 139: 3752-3762.

7. Huo J, Luo RH, Metz SA, Li G. Activation of caspase-2 mediates the apoptosis induced by GTP-depletion in insulin-secreting (HIT-T15) cells. Endocrinology 2002; 143: 1695-1704.

8. Huo J, Metz SA, Li G. Role of tissue transglutaminase in GTP depletion-induced apoptosis of insulin-secreting (HIT-T15) cells. Biochem Pharmacol 2003; 66: 213-223.
9. Sandberg JO, Andersson A, Sandler S. Exposure of rat pancreatic islets to RS-61443 inhibits beta-cell function. Transplantation 1993; 56: 1197-1201.

10. Sandler S, Sandberg JO, Andersson A. RS-61443-induced glucose intolerance in mice. Transplant Proc 1994; 26: 741-742.

11. Kim JY, Huh KH, Park YJ, Fang Y, Kang CM, Kim YS. Molecular mechanisms of cell death of mycophenolic acid-treated primary isolated rat islets: implication of mitogen-activated protein kinase activation. Transplant Proc 2008; 40: 2575-2577.

12. Park YJ, Ahn HJ, Chang HK, Kim JY, Huh KH, Kim MS et al. The RhoGDI-alpha/JNK signaling pathway plays a significant role in mycophenolic acid-induced apoptosis in an insulin-secreting cell line. Cell Signal 2009; 21: 356-364.

13. Park YJ, Ahn HJ, Kim YS, Cho Y, Joo DJ, Ju MK. Illumina-microarray analysis of mycophenolic acid-induced cell death in an insulin-producing cell line and primary rat islet cells: new insights into apoptotic pathways involved. Cell Signal 2010; 22: 1773-1782.

14. Chen J, Saxena G, Mungrue IN, Lusis AJ, Shalev A. Thioredoxin-interacting protein: a critical link between glucose toxicity and beta-cell apoptosis. Diabetes 2008; 57: 938-944.

15. Kim WH, Lee JW, Gao B, Jung MH. Synergistic activation of JNK/SAPK induced by TNF-alpha and IFN-gamma: apoptosis of pancreatic beta-cells via the p53 and ROS pathway. Cell Signal 2005; 17: 1516-1532.

16. Ueda S, Masutani H, Nakamura H, Tanaka T, Ueno M, Yodoi J. Redox control of cell death. Antioxid Redox Signal 2002; 4: 405-414.

17. Holmgren A. Thioredoxin. Annu Rev Biochem 1985; 54: 237-271.

18. Ago T, Sadoshima J. Thioredoxin1 as a negative regulator of cardiac hypertrophy. Antioxid Redox Signal 2007; 9: 679-687.

19. Watson WH, Yang X, Choi YE, Jones DP, Kehrer JP. Thioredoxin and its role in toxicology. Toxicol Sci 2004; 78: 3-14.

20. Arai RJ, Masutani H, Yodoi J, Debbas V, Laurindo FR, Stern A et al. Nitric oxide induces thioredoxin-1 nuclear translocation: possible association with the p21Ras survival pathway. Biochem Biophys Res Commun 2006; 348: 1254-1260.

21. Ago T, Sadoshima J. Thioredoxin and ventricular remodeling. J Mol Cell Cardiol 2006; 41: 762-773.

22. Bertini R, Howard OM, Dong HF, Oppenheim JJ, Bizzarri C, Sergi R et al. Thioredoxin, a redox enzyme released in infection and inflammation, is a unique chemoattractant for neutrophils, monocytes, and T cells. J Exp Med 1999; 189: 1783-1789.

23. Haendeler J, Hoffmann J, Tischler V, Berk BC, Zeiher AM, Dimmeler S. Redox regulatory and anti-apoptotic functions of thioredoxin depend on S-nitrosylation at cysteine 69. Nat Cell Biol 2002; 4: 743-749.

24. Saitoh M, Nishitoh H, Fujii M, Takeda K, Tobiume K, Sawada $Y$ et al. Mammalian thioredoxin is a direct inhibitor of apoptosis signal-regulating kinase (ASK) 1. EMBO J 1998; 17: 2596-2606.

25. Sasada T, Iwata S, Sato N, Kitaoka Y, Hirota K, Nakamura K et al. Redox control of resistance to cis-diamminedichloroplatinum (II) (CDDP): protective effect of human thioredoxin against CDDP-induced cytotoxicity. J Clin Invest 1996; 97: 2268-2276.

26. Fukuse $\mathrm{T}$, Hirata $\mathrm{T}$, Yokomise $\mathrm{H}$, Hasegawa $\mathrm{S}$, Inui $\mathrm{K}$, Mitsui $\mathrm{A}$ et al. Attenuation of ischaemia reperfusion injury by human thioredoxin. Thorax 1995; 50: 387-391.

27. Hotta M, Tashiro F, Ikegami H, Niwa H, Ogihara T, Yodoi J et al. Pancreatic beta cellspecific expression of thioredoxin, an antioxidative and antiapoptotic protein, prevents autoimmune and streptozotocin-induced diabetes. J Exp Med 1998; 188: 1445-1451.

28. Yamamoto M, Yamato E, Toyoda S, Tashiro F, Ikegami H, Yodoi J et al. Transgenic expression of antioxidant protein thioredoxin in pancreatic beta cells prevents progression of type 2 diabetes mellitus. Antioxid Redox Signal 2008; 10: 43-49.

29. Chou FC, Sytwu HK. Overexpression of thioredoxin in islets transduced by a lentiviral vector prolongs graft survival in autoimmune diabetic NOD mice. J Biomed Sci 2009; 16: 71-81.

30. Ikegami H, Ono M, Fujisawa T, Hiromine Y, Kawabata Y, Yamato E. Molecular scanning of the gene for thioredoxin, an antioxidative and antiapoptotic protein, and genetic susceptibility to type 1 diabetes. Ann N Y Acad Sci 2008; 1150: 103-105.

31. Cho Y, Huh KH, Park YJ, Do JH, Joo DJ, Kim MS et al. Cellular function of RhoGDI-alpha mediates the cycling of Rac1 and the regulation of pancreatic beta cell death. Transplant Proc 2012; 44: 1083-1085.

32. Kowluru A. Friendly, and not so friendly, roles of Rac1 in islet beta-cell function: lessons learnt from pharmacological and molecular biological approaches. Biochem Pharmacol 2011; 81: 965-975.

33. Morgan D, Oliveira-Emilio HR, Keane D, Hirata AE, Santos da Rocha M, Bordin S et al. Glucose, palmitate and pro-inflammatory cytokines modulate production and activity of a phagocyte-like NADPH oxidase in rat pancreatic islets and a clonal beta cell line. Diabetologia 2007; 50: 359-369.

34. Subasinghe W, Syed I, Kowluru A. Phagocyte-like NADPH oxidase promotes cytokineinduced mitochondrial dysfunction in pancreatic beta-cells: evidence for regulation by Rac1. Am J Physiol Regul Integr Comp Physiol 2011; 300: R12-R20.

35. Syed I, Jayaram B, Subasinghe W, Kowluru A. Tiam1/Rac1 signaling pathway mediates palmitate-induced, ceramide-sensitive generation of superoxides and lipid peroxides and the loss of mitochondrial membrane potential in pancreatic beta-cells. Biochem Pharmacol 2010; 80: 874-883. 
36. Brissova M, Fowler MJ, Nicholson WE, Chu A, Hirshberg B, Harlan DM et al. Assessment of human pancreatic islet architecture and composition by laser scanning confocal microscopy. J Histochem Cytochem 2005; 53: 1087-1097.

37. Cabrera O, Berman DM, Kenyon NS, Ricordi C, Berggren PO, Caicedo A. The unique cytoarchitecture of human pancreatic islets has implications for islet cell function. Proc Nat Acad Sci USA 2006; 103: 2334-2339.

38. Kim JY, Yoon SY, Park J, Kim YS. Mycophenolic acid induces islet apoptosis by regulating mitogen-activated protein kinase activation. Transplant Proc 2006; 38 : 3277-3279.

39. Matthews JR, Wakasugi N, Virelizier JL, Yodoi J, Hay RT. Thioredoxin regulates the DNA binding activity of NF-kappa B by reduction of a disulphide bond involving cysteine 62 . Nucleic Acids Res 1992; 20: 3821-3830.

40. D'Amico E, Hui H, Khoury N, Di Mario U, Perfetti R. Pancreatic beta-cells expressing GLP-1 are resistant to the toxic effects of immunosuppressive drugs. J Mol Endocrinol 2005; 34: 377-390.
41. Tao L, Gao E, Bryan NS, Qu Y, Liu HR, Hu A et al. Cardioprotective effects of thioredoxin in myocardial ischemia and reperfusion: role of S-nitrosation [corrected]. Proc Natl Acad Sci USA 2004; 101: 11471-11476.

42. Liu Y, Min W. Thioredoxin promotes ASK1 ubiquitination and degradation to inhibit ASK1mediated apoptosis in a redox activity-independent manner. Circ Res 2002; 90: 1259-1266.

Cell Death and Disease is an open-access journal published by Nature Publishing Group. This work is licensed under a Creative Commons Attribution-NonCommercialShareAlike 3.0 Unported License. To view a copy of this license, visit http://creativecommons.org/licenses/by-nc-sa/3.0/

Supplementary Information accompanies this paper on Cell Death and Disease website (http://www.nature.com/cddis) 